Journal of Business and Tourism

Volume 04 Number 02

July-December, 2018

\title{
Liquidity Choice: A Study of Theoretical and Empirical Mystery in Context of Pakistan
}

\author{
DR. NAVEED HUSSAIN SHAH \\ Assistant Professors, University of Swabi \\ Dr.naveedshah@uoswabi.edu.pk \\ DR. MUHAMMAD ARIF \\ Assistant Professors, University of Swabi \\ Dr.arif@uoswabi.edu.pk \\ DR. MUHAMMAD ASAD KHAN \\ Assistant Professor, National University of Modern Languages \\ Masad@numl.edu.pk \\ DR. MUHAMMAD FAIZAN MALIK \\ Assistant Professor, Institute of Business Studies and Leadership \\ Abdul Wali Khan University, Mardan
}

\begin{abstract}
Contextual difference and inclusion of demographics as independent as well as new dimension of Liquidity preferencemade the study unique and novel in its essence. Empirical result of the correlation matrix is showing aninsignificant correlation of liquidity preference with gender, age, education, experience, annual income, annual savings, occupation and location.Regression analysis depicts significant relationship of liquidity preferencewith Education and Savings given by t-values -2.129, 2.190 and p-values -0 .620, 0.029 respectively.Liquidity preference is showing an insignificant relationship with Gender, Age, Experience, Income and Occupation given by t-values 0.117, 0.076, -1.220, -0.708,-0.144 and p-values .009, 006,-..120,-.075 and -.011 respectively.
\end{abstract}

Key words: Liquidity preference, Correlation matrix, regression.

\section{Introduction}

An exploration of Investor demographic context had been under study and suggestion by a number of researchers like H. Martin, G. Joseph and Eisenhower (2001), J. John, Burnett, P. A. Bruce (1984) and J. A. Nancy, B. Alexandra (2006). Fregert (2003)work considered an investment appropriate if it gives excess return as compare to it own worth. Bonds are considered as most safe of all the investment and investor also pursue some other riskier forms of investment.Investors are in search of an investment opportunity which had a meager cost of switching into another that researcher termed as Liquidity.Makower and Marschak (1938) consider money as the most liquid and steering instrument of engulfing all assets into its only form.Hirshleifer (1968)study defined liquidity as its potential of being easily and immediately utilizable in dire needs.Liquidity of assets provides a unique feature of medium of exchange hence money is the most liquid with desirability of widely used as 
medium of exchange.Individuals are looking for same feature in all investable assets. As it was detailed in Lippman and McCall (1986)study while ranking assets and commodities on the basis of liquidity as compare to the most liquid termed as money. Salehi, Talebnia, and Ghorbani (2011) considered liquidity as the cash conversion trait of a financial instrument at market price and is one of the main functions of capital markets. It is highly cited in literature in finance that individual prefer high liquidity compare to returns.

\section{Research Objectives}

Following are the objectives of the study

- To find correlate demographic variables and investment preferences, liquidity.

- To find out the effect of demographic variables on investment preferences,liquidity.

- To suggest and recommend for investment in term of the findings and conclusions of the study.

\subsection{Hypotheses of the Study}

\section{Hypotheses for Liquidity Choice}

$\mathrm{H}_{1}$ : Gender and liquidity exhibit a significant relationship.

$\mathrm{H}_{2}$ :Age and liquidityexhibits a significant relationship.

$\mathrm{H}_{3}$ :Education and liquidityexhibits a significant relationship.

$H_{4}$ :Experience level and liquidityexhibits a significant relationship.

$H_{5}$ :Annual income and liquidityexhibits a significant relationship.

$H_{6}$ :Annual savings and liquidityexhibits a significant relationship.

$H_{7}:$ Occupation and liquidityexhibits a significant relationship.

$H_{8}$ :Location and liquidityexhibits a significant relationship.

\section{Research Methodology}

This section describe research design, data collection, Conceptual back ground and theoretical Frame work Sampling procedure and data analysis.

\section{1 Research Design}

It is a descriptive and correlational study revealing the relationship between demographic factors and investment preferences in Pakistan. Leimberg, Satinsky, LeClair, and Doyle (1993) was adopted concerning contextual grounds mainly, specifically demographic factors effect on Liquidity preferences.

\subsection{Data Collection}

Considering simple random sampling technique data was collected through questionnaire from all the business students given by (Dubinsky \& Rudelius, 1980)comprising of major

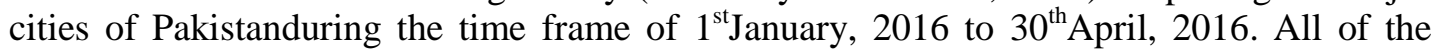
participants were informedthrough a covering letter and a business graduate communicatorabout the purpose of the study. Kline (2000) argued that it is justified that the sample of 382 in a prescribed statement is to have more than or equal to 2 sets of data for each item in the questionnaire or for each construct there should be at least more than or equal to 15 data sets (Pedhazur,1982). This justification shows that the study would be useless if less than 102 as mentioned by the statement of(Kline, 2000)or should be above 165 as argued by (Kline, 2000). The sample size of 382 is utilized by this study ahead of both the mentioned levels i.e.102 and 165 . While adopting simple random techniques 500 questionnaires were distributed among six cities in Pakistan collecting 400 of which 382 were posted correctly and inappropriately filled were discarded. 


\subsection{Conceptual Background and Theoretical Framework}

The basic input of the of the financial management model given by (Leimberg et al., 1993).Grable (1997)work also encourages pursuing demographic as a differentiating and classifying factors. Current study is to find out the relationship between demography and investment preferences in perspective of liquidity choice in Pakistan. As per literature it is a deemed appropriate model.

\subsection{Data Analysis Techniques}

The data was analyzed through SPPSS version 21 by using regression and correlation techniques. The data was investigated for missing values and outliers and inappropriately filled questionnaires and found no outlier.

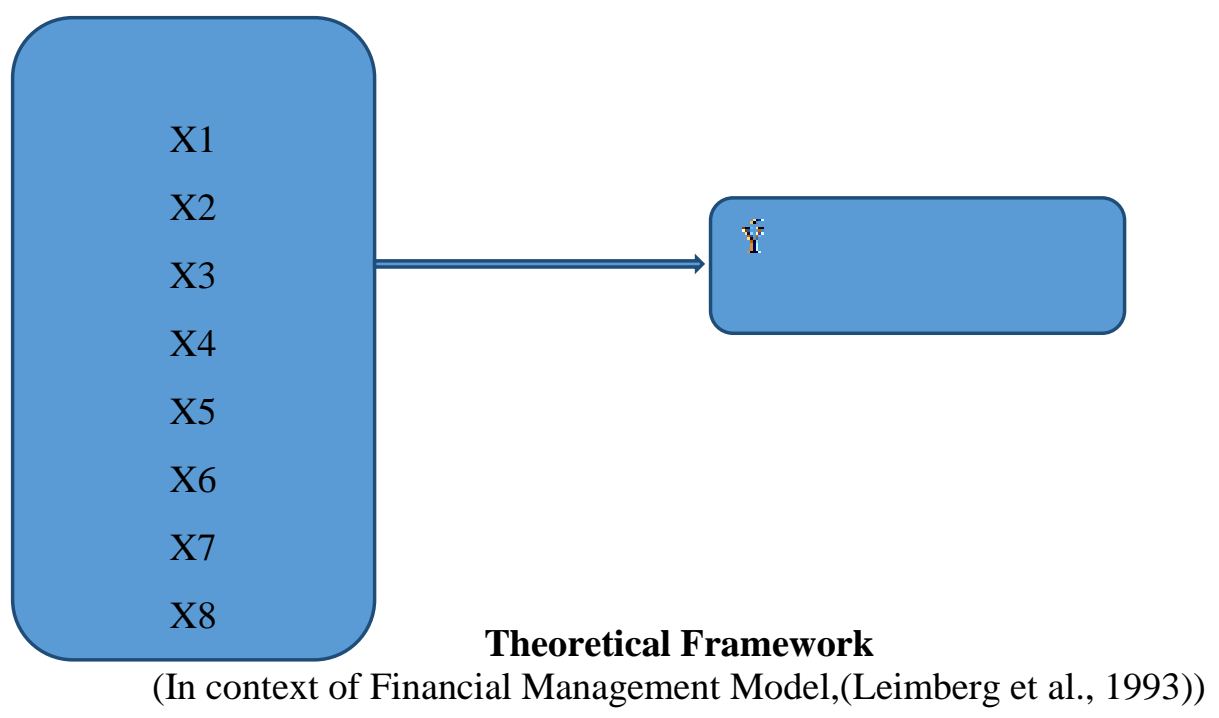

\subsection{Multiple Linear Regression Model}

Mcneil, Newman, and Fraas (2011)considered multiple linear regressionfor finding relationship betweenpredictor and predicted variable of either both categorical, categorical and continues or both continues. Analysis was made using a $0.05 \alpha$ level. A poweranalysis (Cohen, 1988) was made for an $n=382, \alpha=0.05$, and for a medium size effect $(0.15)$ with 7 variables, power $=0.99$. For a small size effect $(0.020) n=382, \alpha=0.05$ power $=0.6$

$$
\begin{aligned}
& Y=\beta 1 \mathrm{X}_{0}+\beta 2 \mathrm{X}_{1}+\beta 3 \mathrm{X} 2_{0}+\beta 4 \mathrm{X} 2_{1}+\beta 4 \mathrm{X}_{2}+\beta 5 \mathrm{X}_{0}+\beta 7 \mathrm{X}_{1}+\beta 8 \mathrm{X} 3_{2} \\
& +\beta 9 \mathrm{X}_{3}+\beta 10 \mathrm{X}_{4}+\beta 11 \mathrm{X} 4_{0}+\beta 12 \mathrm{X}_{1}+\beta 13 \mathrm{X}_{2}+\beta 14 \mathrm{X} 4_{3} \\
& +\beta 14 \mathrm{X}_{4}+\beta 15 \mathrm{X5}_{0}+\beta 16 \mathrm{X5}_{1}+\beta 17 \mathrm{X5}_{2}+\beta 18 \mathrm{X} 6_{0}+\beta 19 \mathrm{X6}_{2} \\
& +\beta 20 \times 6_{3}+\beta 21 \mathrm{X6}_{4}+\beta 22 \times 6_{5}+\beta 23 \mathrm{X6}_{6}+\beta 24 \mathrm{X}_{0}+\beta 25 \mathrm{X}_{1} \\
& +\beta 26 \mathrm{X7}_{2}+\beta 27 \mathrm{X} 7_{3}+\beta 28 \mathrm{X7}_{4}+\beta 29 \mathrm{X} 8_{0}+\beta 30 \mathrm{X}_{1}+\beta 31 \mathrm{X8}_{2} \\
& +\beta 32 \mathrm{X8}_{3}+\beta 33 \mathrm{X8}_{4}
\end{aligned}
$$

Whereas $\beta$ represent coefficient of the regression and other symbols represents the following illustrated as $Y=$ Liquidity 
$\mathrm{X} 1_{0}=$ Female, $\mathrm{X} 1_{1}=$ Male

$\mathrm{X} 2_{0}=$ Less than 25 years age, $X 2_{1}=$ between 25 to 40 years, $X 2_{3}=$ Greater than 40 years

$\mathrm{X} 3_{0}=$ Less than Rs. 5 lack, $\mathrm{X} 3_{1}=$ Rs. 5 lack to Rs. 10 lack, $\mathrm{X} 3_{2}=$ Rs. 10 to Rs. 15 lack,

$\mathrm{X}_{3}=$ Rs. 15 to Rs. 20 lack, $\mathrm{X}_{4}=$ Rs. 20 lack and above

$\mathrm{X} 4_{0}=$ Less than $5 \%$ of income, $\mathrm{X} 4_{1}=5 \%$ to $10 \%$ of income, $\mathrm{X} 4_{2}=10 \%$ to $20 \%$ of income

$\mathrm{X} 4_{3}=20 \%$ to $30 \%$ of income, $\mathrm{X} 4_{4}=30 \%$ and above

$\mathrm{X5}_{0}=$ Other, $\mathrm{X} 5_{1}=$ Own business or Partnership, $\mathrm{X} 5_{2}=$ Public, $\mathrm{X} 5_{3}=$ Private

$\mathrm{X} 6_{0}=$ Lahore, $\mathrm{X} 6_{1}=$ Peshawar, $\mathrm{X} 6_{2}=$ Islamabad, $4 \mathrm{X} 6_{3}=$ Karachi, X6 $6_{4}=$ Quetta, X6 $6_{5}=$ Chitraal

$\mathrm{X} 7_{0}=$ Less than High School, $\mathrm{X} 7_{0}=$ High School, $\mathrm{X} 7_{0}=$ Diploma, $\mathrm{X} 7_{0}=$ Graduate

$\mathrm{X} 7_{0}=$ Post Graduate

$\mathrm{X} 8_{0}=$ Less than 1 year, $X 8_{0}=1$ to 3 years, $X 8_{0}=3$ to 5 years, $X 8_{0}=5$ to 8 years

$\mathrm{X} \mathrm{8}_{0}=8$ years and above

The list of dependent and independent variables are as follows

\subsubsection{Dependent Variables}

The issue under consideration is known as predicted or dependent variable and here it is liquidity preferences described below

\subsubsection{Liquidity}

A quality of urgent resale with little effect on it prime worth is called liquidity and any asset bearing this trait is termed as liquid asset.

Lippman and McCall (1986)was used in designing questionnaire of the study. It is composed of LQ1 to LQ9 with five point likert scale. First sample question is with abbreviation LQ1 is "I am worried about the immediate rise in consumption or worrying of missing an opportunity while making an investment" with response 1 for true and 5 for never true.

\subsubsection{Independent Variables}

Demographic profile with multiple variables was considered for its effect on dependent variable through relevant statistical tests.

\subsubsection{Demographics Variables}

The demographic profile are exhibiting the variables of age, gender, income level, saving level, education, job nature, Location and work experience. There is an existence of vast literature to consider demography as independent variable and taking Investment preference, liquidity as criterion variable.

\section{Analysis}

It is made in order to test the established hypothesis through statistical language and this section is described as descriptive, frequencies and graph as well as include correlation matrix and regression given below

\subsection{Descriptive}

Descriptive statistic and frequencies of the various respondents towards various slabs of demographics as well as its relation with investment preferences, liquidity is under consideration. The list of the work is as under. 
Table 1: Descriptive Statistics

Descriptive Statistics

\begin{tabular}{|c|c|c|c|c|c|c|c|c|c|}
\hline \multirow[t]{2}{*}{$\mathrm{N}$} & \multirow[t]{2}{*}{ Min } & \multirow[t]{2}{*}{$\operatorname{Max}$} & \multirow[t]{2}{*}{ Mean } & \multirow{2}{*}{$\begin{array}{l}\text { Std. } \\
\text { Dev. }\end{array}$} & \multirow[t]{2}{*}{ Variance } & \multicolumn{2}{|c|}{ Skewness } & \multicolumn{2}{|c|}{ Kurtosis } \\
\hline & & & & & & Statistic & $\begin{array}{l}\text { Std. } \\
\text { Error }\end{array}$ & Statistic & $\begin{array}{l}\text { Std. } \\
\text { Error }\end{array}$ \\
\hline 38 & 2.13 & 4.88 & 3.7147 & .60832 & .370 & -.494 & .125 & -.547 & .249 \\
\hline
\end{tabular}

Table 1 reveals mean values of 3.7147 for Liquidity with standard deviation of 0.60 exhibiting variance for liquidity preference as response. It shows that the data is negatively skewed as evident fromskewness and kurtosis of the predictor.

\subsection{Reliability}

Table 2: Reliability of the Questionnaire

\begin{tabular}{lccc}
\hline Variables & Cronbach's Alpha & Items & No of observations \\
\hline$Y$ & 0.675 & 8 & 382 \\
\hline
\end{tabular}

Reliability statistics of 0.675 in table 2 forliquidity with as8items is greater than 0.6 as stated in the study ofNunnully\& Bernstein (1994) showing reliable predictor.

\subsection{Correlations}

\subsubsection{Correlation among the Variables}

Interpretation of correlationtable for the different variables of the study are expressed in the correlation table.

\subsubsection{Variables exhibiting significant correlations}

\subsubsection{Variables exhibiting insignificant correlations}

Table 3 display an insignificant relationship among variable of study named as Liquidity,Gender,Age,Education,Experience,Annual income,Annual Savings, Occupation and Location given by the correlation coefficient figures and respective p-values-.103,.074,$0.010,-0.016,-0.059,0.037,0.053,0.062$ and -0.087 and $0.044,0.151,0.839,0.758,0.250,0.475,0.303,0.230,0.088$ respectively.

\subsection{Regression for Liquidity as Predictor}

\subsubsection{Interpretations of Adjusted $R^{2}$ and $F$ for Liquidity}

The table 4presents R square and F value for model fitness. Showing an F value equal 606 reflecting fitness of the mode and adjusted $\mathrm{R}$ square 97 express variation in the value of predictor caused by explanatory variablein the model.

\subsubsection{Significant relationships of Liquidity with Education and Savings}

Table 4displaying regression result for liquidity evidencing a significance for education and savings whereas as other demographics factors are insignificant. Other things remain same education at graduate level is displays significance with liquidity given by $\mathrm{t}$ value of -2.129 
$>2$ and $\mathrm{p}-$ value -0.620 at 5 percent confidence interval. However coefficient of -0.620 suggest that while varying across Education slabs bring negative variation of -0.620 time in Liquidity showing lower tendency towards High liquid assets.

Other things remain same saving at level of 5 to 10 percent of income per year displays significant relationship with liquidity given by t value $2.190>2$ and $p$-value 0.029 . So for coefficient of 0.175 suggests that moving across different Saving slabs bring a positive change of 0.175 time in Liquidity displaying high tendency of keeping high liquid assets.

Keeping other factors constant demographic belonging as given by location in Pakistan displays significance with Liquidity given by t value 57,39,33,27, 25 and $29>2$ and p-value 0.000 . However coefficient of 3.654, 4.023, 4.010, 3.938, 3.018 and 3.833 represents residential aspect given by Karachi, Lahore, Peshawar, Islamabad, Quetta and Chitraldisplays variation in residence bringing a positive variation of 3.654, 4.023, 4.010, 3.938, 3.018 and 3.83 in Liquidity suggesting high preference for liquidity option.

Table 3

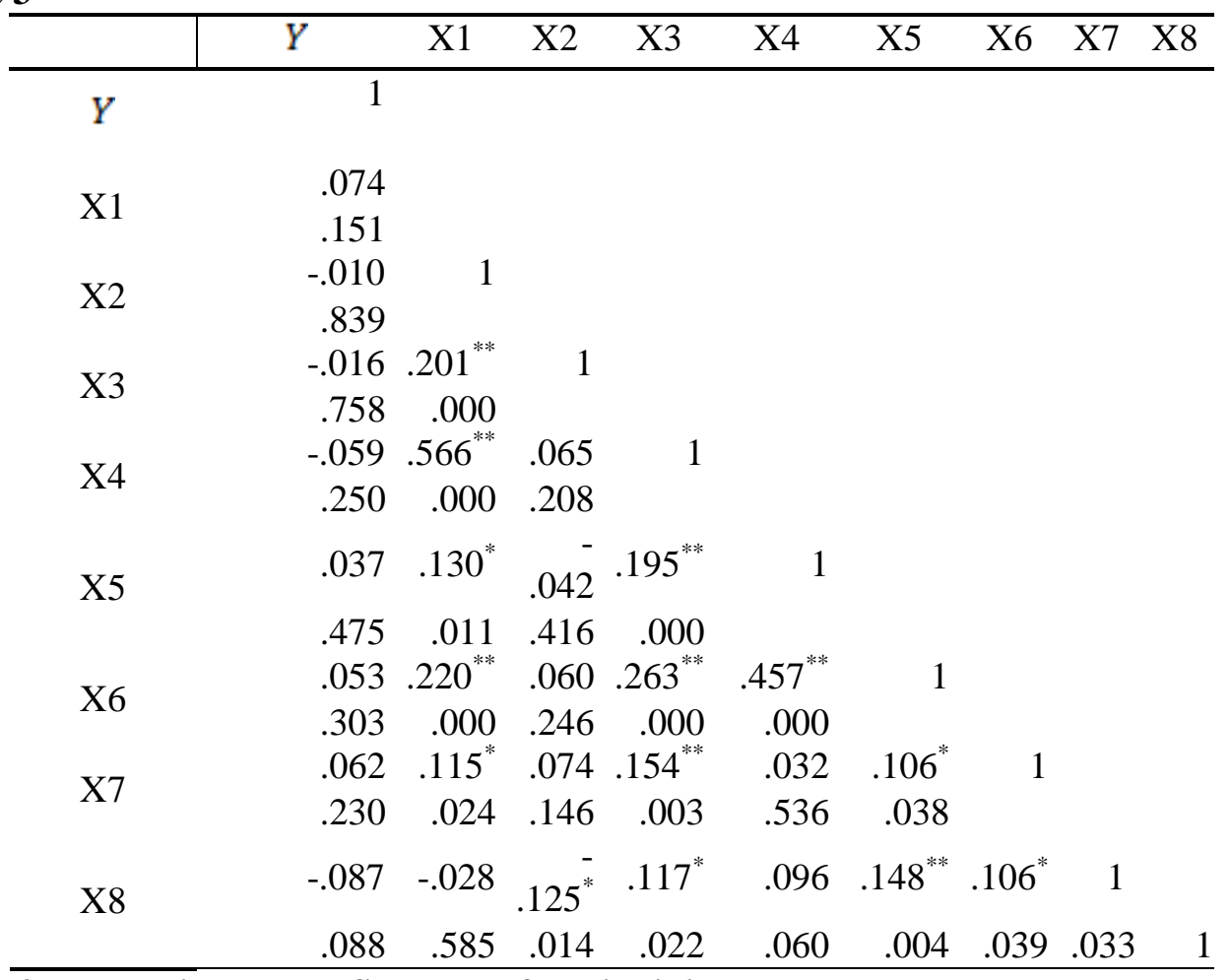

Table 4: Regression Model Summary for Liquidity Model Summary

\begin{tabular}{lrrrr}
\hline Model & R & R Square & Adjusted R Square & $\begin{array}{c}\text { Std. Error of the } \\
\text { Estimate }\end{array}$ \\
\hline 1 & $.990^{\mathrm{a}}$ & .980 & .978 & .55869 \\
\hline
\end{tabular}




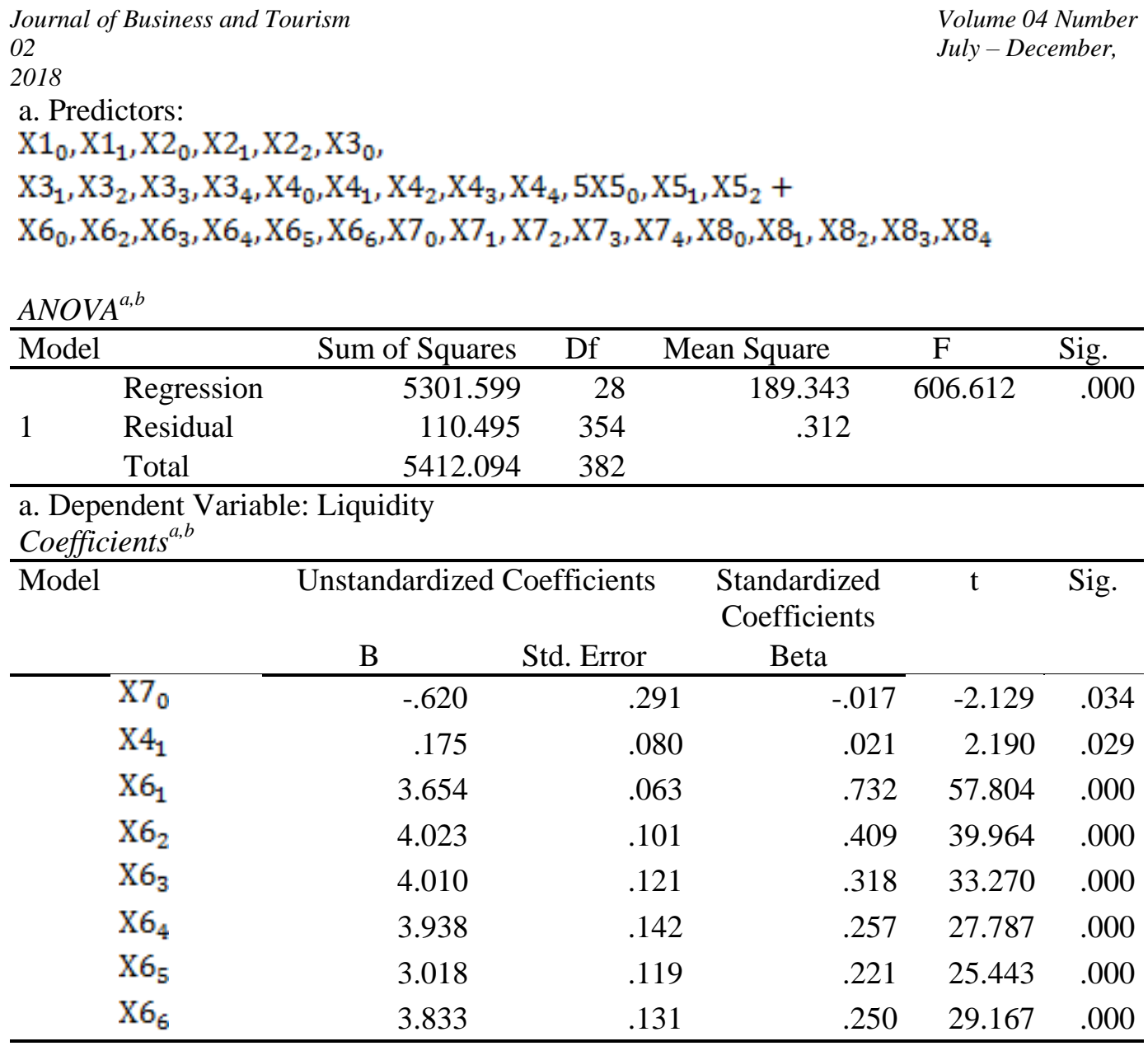

a. Dependent Variable: Liquidity

b. Linear Regression through the Origin

Concluding a significant relationship between education, saving and investment preferences, liquidity given by (Grable, 2000).Liquidity with rest of the variables evidence by correlation is out of the demographic context drawn from insignificant correlation.Saving is key factor of investment choices revealed by significant relationship.Liquidity choiceas per education and locality individual with some saving will preferinvestment in liquid assets in Pakistan.Education a matteringfactor in the choice for liquidity whereas experienced individual prefer illiquid assed like property etc. As opposed to other research findings (Grable \& Joo, 2000; Hanna et al., 1998)and in favor of the Riley Jr and Chow (1992),McInish et al. (1993) andKlos et al. (2005).

\section{Conclusion}

An evidencedof fruitful link of stake holder with liquidity choice suggest that business students prospective investors will try to exploit existing opportunities and will bring innovations in the businesses. While choosing contextfor decision making with liquidity preference. 
Journal of Business and Tourism

Volume 04 Number

02

2018

July-December,

\section{References}

Cohn, R. A., Lewellen, W. G., Lease, R. C., \& Schlarbaum, G. G. (1975). Individual investor risk aversion and investment portfolio composition. THE JOURNAL OF FINANCE, 30(2), 605-620.

Dubinsky, A. J., \& Rudelius, W. (1980). Ethical beliefs: how students compare with industrial salespeople. Paper presented at the Proceedings of the American Marketing Association Educators Conference.

Fregert, K. (2003). och Jonung, L: Makroekonomi.

Grable, J. E. (1997). Investor risk tolerance: Testing the efficacy of demographics as differentiating and classifying factors. Virginia Polytechnic Institute and State University.

Grable, J. E. (2000). Financial risk tolerance and additional factors that affect risk taking in everyday money matters. Journal of Business and Psychology, 14(4), 625-630.

Grable, J. E., \& Joo, S. (2000). A cross-disciplinary examination of financial risk tolerance. Consumer Interests Annual, 46(91), 151-157.

Haliassos, M., \& Bertaut, C. C. (1995). Why do so few hold stocks? the economic Journal, 1110-1129.

Makower, H. and Marschak, J. (1938). Assets, Prices and Monetary Theory. Economica,5, 261-287.

Hirshleifer, J. (1968). VLiquidity, uncertainty and the accumulation of assets. V CORE Discus \$ sion Paper(6810).

Jain, D., \& Kothari, R. (2012). Investors' attitude towards Post Office Deposits SchemesEmpirical Study in Udaipur district, Rajasthan. International Journal of Marketing and Technology, 2(7), 255.

Kline, P. (2000). A psychometrics primer: Free Assn Books.

Leimberg, S. R., Satinsky, M. J., LeClair, R. T., \& Doyle, R. J. (1993). The Tools and Techniques of Financial Planning (4th ed.). Cincinnati, $\mathrm{OH}$ : National Underwriter.

Lippman, S. A., \& McCall, J. J. (1986). An Operational Measure of Liquidity. The American Economic Review, 76(1), 43-55.

Lytton, R. H., Garman, E., \& Dail, P. W. (1987). A systems approach to analyzing critical financial management competencies. Paper presented at the Proceedings of the American Council on Consumer Interests annual meeting, Denver, CO.

McInish, T. H. (1982). Individual investors and risk-taking. Journal of economic psychology, 2(2), 125-136.

McInish, T. H., Ramaswami, S. N., \& Srivastava, R. K. (1993). Do More Risk-Averse Investors Have Lower Net Worth and Income? Financial Review, 28(1), 91-106.

Mcneil, K., Newman, I., \& Fraas, J. W. (2011). Designing General Linear Models to Test Research Hypotheses: University Press Of America.

Nunnally, J. C., \& Bernstein, I. (1994). The assessment of reliability. Psychometric theory, 3(1), 248-292.

Riley Jr, W. B., \& Chow, K. V. (1992). Asset allocation and individual risk aversion. Financial Analysts Journal, 48(6), 32-37. 
Journal of Business and Tourism

Volume 04 Number

02

2018

July-December,

Salehi, M., Talebnia, G., \& Ghorbani, B. (2011). A study of the relationship between liquidity and stock returns of companies listed in Tehran Stock Exchange. World Applied Sciences Journal, 12(9), 1403-1408. 